\title{
Reporting of post-operative rehabilitation interventions for Total knee arthroplasty: a scoping review
}

Nora Bakaa* (D), Lu Hsi Chen, Lisa Carlesso, Julie Richardson and Luciana Macedo

\begin{abstract}
Objective: The aim of this study was to evaluate the completeness of reporting of exercise adherence and exercise interventions delivered as part of clinical trials of post-operative total knee replacement (TKA) rehabilitation.

Design: Scoping review

Literature search: A literature search was conducted in PubMed, EMBASE, AMED, CINAHL, SPORTDiscus and Cochrane Library.

Study selection criteria: All randomized controlled trials $(R C T)$ that examined post-operative exercise-based interventions for total knee arthroplasty were eligible for inclusion. Studies that were multifactorial or contained exercise interventions for both hip and knee arthroplasty were also included.

Data synthesis: The definition, type of measurement used and outcome for exercise adherence were collected and analyzed descreptively. Quality of reporting of exercise interventions were assessed using the Consensus for Exercise Reporting Tool (CERT) and the Cochrane Risk of Bias Tool.

Results: There were a total of 112 RCTs included in this review. The majority of RCTs $(63 \%, n=71)$ did not report exercise adherence. Only 23\% ( $n=15)$ of studies provided a definition of adherence. RCTs were of poor quality, with $85 \%(n=95)$ of studies having high or unclear risk of bias. Reporting of exercise interventions was poor, with only 4 items (of 19) (21\%) of the CERT adequately reported (88-99\%), with other items not fulfilled on at least 60\% of the RCTs. There were no RCTs that had fulfilled all the criteria for the CERT.

Conclusion: The RCTs included in this study poorly reported exercise adherence, as well as description of the postoperative TKA rehabilitation intervention. Future RCTs should use valid and reliable measures of adherence and a proper tool for reporting of exercise interventions (e.g., CERT, TiDER).
\end{abstract}

Pre-registration: OSF: https://osf.io/9ku8a/

Keywords: TKA, Total knee arthroplasty, Exercise rehabilitation, CERT, Adherence, Scoping review

*Correspondence: bakaanh@mcmaster.ca; norabakaa@gmail.com

School of Rehabilitation Sciences, Faculty of Health Sciences, McMaster University, Institute of Applied Health Sciences, Room 403, 1400 Main St. W., Hamilton, ON L8S 1C7, Canada

(c) The Author(s). 2021 Open Access This article is licensed under a Creative Commons Attribution 4.0 International License, which permits use, sharing, adaptation, distribution and reproduction in any medium or format, as long as you give appropriate credit to the original author(s) and the source, provide a link to the Creative Commons licence, and indicate if changes were made. The images or other third party material in this article are included in the article's Creative Commons licence, unless indicated otherwise in a credit line to the material. If material is not included in the article's Creative Commons licence and your intended use is not permitted by statutory regulation or exceeds the permitted use, you will need to obtain permission directly from the copyright holder. To view a copy of this licence, visit http://creativecommons.org/licenses/by/4.0/ The Creative Commons Public Domain Dedication waiver (http://creativecommons.org/publicdomain/zero/1.0/) applies to the data made available in this article, unless otherwise stated in a credit line to the data. 


\section{Key points}

1. Authors should use valid and reliable outcome measures of exercise adherence across all study treatment arms.

2. Authors should clearly define exercise adherence and use a continuous measure (rather than a cut-off) to avoid reporting bias.

3. In addition to using an RCT reporting guideline, authors should include an exercise reporting tool (e.g., TiDER or CERT).

4. Authors should adequately report exercise interventions even if it is an adjunct to the main intervention (e.g., electrotherapy plus exercise, control group, etc.).

\section{Background}

Rehabilitation, specifically therapeutic exercise, is one of the most recommended interventions for improving health outcomes after total knee arthroplasty (TKA) [1]. A recent meta-analysis of 27 studies provided low-tomoderate quality evidence that exercise interventions (e.g. aerobic exercises, strength training) improved patient outcomes after TKA [2]. There was low quality evidence for pain reduction (SMD - 0.65, 95\% CI [- 1.22, $-0.08]$ ), and moderate quality evidence for improved physical function (SMD $-0.40,95 \%$ CI $[-0.74,-0.07$ ) at 8-weeks follow-up [2]. While the benefits of exercise have been highlighted within the literature, studies that have assessed rehabilitation after TKA often lack detailed descriptions of the intervention (e.g. dosage, frequency, intensity, duration, etc.), thereby limiting translation to clinical practice [3-5].

Clinical guidelines for post-operative rehabilitation for TKA often do not provide detailed information about the recommended interventions, [6, 7] leading to variation in care and treatment approaches that are refined by the treating practitioners. A systematic review assessing rehabilitation guidelines for post-operative TKA concluded that proper instructions and adherence to rehabilitation can improve post-operative recovery and improve physical activity levels post-operatively [8]. Further, there is evidence to suggest that lack of exercise after TKA may lead to poor post-operative outcomes, including increased pain and functional disability [1]. However, there is very little evidence surrounding patient adherence to exercise recommendations after TKA, which may also impact the implementation of these interventions [8].

Exercise adherence can be defined as: "the extent to which individuals undertake prescribed behaviour accurately and at the agreed frequency, intensity and duration." [9] Despite the importance of adherence to exercise interventions, there are no studies that focus on adherence to therapeutic exercise after TKA. In a recent systematic review, some studies that assessed effectiveness of exercise after TKA have reported adherence to exercise interventions, however, it is unclear how adherence is defined (e.g. compliance, concordance, etc.) or measured within a randomized controlled trial [5].

Therefore, the aim of this study was to evaluate completeness of reporting of exercise adherence and exercise interventions delivered as part of clinical trials of postoperative TKA rehabilitation. While systematic reviews evaluate a specific range of studies to answer focused questions of effectiveness, scoping reviews often have a broader mandate to examine the range and extent of research activity in a field [10]. In this study, a scoping review was used to answer the following questions:

1) How is exercise adherence measured and reported in post-operative TKA rehabilitation programs?

2) How is exercise adherence defined in post-operative TKA research?

3) How complete is the reporting of exercise interventions (e.g., frequency, intensity, etc.) in post-operative TKA rehabilitation?

\section{Methods}

A scoping review was chosen for this study to examine the characteristics of exercise adherence and assess the quality of reporting of exercise intervention in postoperative TKA.

This scoping review followed the Preferred Reporting Items for Systematic Reviews and Meta Analyses (PRIS MA) guidelines for scoping reviews [11]. We also used Arksey \& O'Malley's [12] methodological framework, modified by Levac et al., [10] to guide this scoping review. This framework included the following stages: 1) Identifying the research question; 2) Identifying relevant studies; 3) Selecting studies; 4) Charting the data, collating, and summarizing; and 5) Reporting the results. This protocol was pre-registered with OSF: https://osf.io/ $9 \mathrm{ku} 8 \mathrm{a} /$.

\section{Inclusion criteria for this review Type of participants}

Studies with adults ( $>18$ years old), that underwent bilateral or unilateral TKA, were included in this review.

\section{Type of studies}

All randomized controlled trials (RCT) that examined post-operative exercise-based interventions (home-based, inpatient, or outpatient) were eligible for inclusion. If the control group was not an exercise intervention, it was still included in this review. An exercise-based intervention was defined as: "an intervention that involved participants completing more than one session of physical exercises 
such as strengthening, flexibility, and/or aerobic activities." [13] If a study was multifactorial (e.g., exercise and education), then the study was included if the primary intervention was exercise. Exercise was considered a primary intervention, if exercise was a major component through the description of the intervention as well as if the effectiveness of the interventions were evaluated using common exercise outcome measures (e.g., pain, function, patient satisfaction with exercise, etc.). If a study contained an exercise intervention for both hip and knee arthroplasty, it was included. No language restrictions were applied. Gray literature studies (e.g., abstracts, conferences, commentaries, editorials), systematic reviews, case studies, psychometric studies, studies where patients with total knee replacement were identified retrospectively were excluded. Studies that included passive forms of exercise (e.g., continuous passive motion) in the primary intervention were excluded.

\section{Search strategy for identifying relevant studies}

A McMaster University Health Sciences librarian was consulted during the process of building the search strategy. A literature search was conducted (April 29, 2020) in PubMed, EMBASE, AMED, CINAHL, SPORTDiscus and Cochrane Library using terms that capture exercise, physical therapy, physiotherapy, rehabilitation, adherence, and TKA (Additional file 1: Appendix A). A limiter for RCTs was placed. There was no limiter for date or language. A hand search of references that cited the included full text articles was conducted (June 22, 2020).

\section{Selection of sources of studies}

Initially, eligible studies were uploaded to the referencing software EndNote, and any duplicates were removed. The final list was then uploaded to Covidence, an online screening and data extraction tool. Each screening step (title/abstract and full text) was performed by two independent reviewers (NB, LC) (Additional file 2: Appendix $\mathrm{B})$. If there were any discrepancies between reviewers a third reviewer was consulted (LM). Prior to each screening step, a pilot screening occurred on the first three studies to ensure standardization for selection criteria between each reviewer. Any discrepancy between reviewers in the pilot screening was discussed to identify any concerns and improve reliability.

\section{Data charting process and items}

One pair of investigators independently extracted data from the remaining studies that fit the inclusion criteria (NB, LC). Data was also extracted from any supplemental resources available for each study. Data was independently exported into a data extraction sheet on Microsoft Excel (See Additional file 3: Appendix C). The data extraction table included study design, sample size, descriptive statistics (e.g., age, sex, etc.), exercise intervention type, duration (e.g., 6 weeks, 12 weeks, etc.), outcome (e.g. pain, disability, etc.), and risk of bias as per the Cochrane Risk of Bias Assessment Tool [14].. To assess completeness of exercise reporting we used the Consensus on Exercise Reporting Template (CERT) [15]. The CERT is a 16 item questionnaire that contains specific items related to reporting of exercise interventions [16]. The final score for the CERT is calculated as a total score out of 19. The CERT has been shown to have good inter-rater agreement in trials that included a wide variety of musculoskeletal conditions (e.g., back \& neck pain, hip \& knee OA) [17]. We assessed the number of items that were reported in each RCT. We considered the reporting to be incomplete if 1 or more items were not reported. To assess exercise adherence, we extracted any definitions of exercise adherence or related terms (e.g., compliance, concordance), and exercise adherence measurements and their outcomes. If there were no explicit mention of any terms that assessed adherence, then general information (e.g., number of sessions attended, completion of exercise diaries) regarding adherence was also included. Outcomes were also collected from the control groups of each included study, as the included studies were parallel RCTs where active interventions were part of the control group. As such, it is important that readers fully understand the components of all interventions included within a study and that the reporting of both interventions allow for replication. Any discrepancies between extractors were assessed by a third-party investigator (LM) if a consensus was not reached.

\section{Synthesis of results \\ Exercise adherence}

Studies were screened electronically for keywords that relate to exercise adherence. Studies were categorized as either reporting exercise adherence (or related terms) or not reporting and presented as a percentage. Studies that reported exercise adherence were assessed for measurement tools used for reporting of exercise adherence (e.g., self-reported patient/practitioner outcomes, accelerometer, etc.), exercise adherence results, and any definitions of exercise adherence. The data from similar outcome measures of exercise adherence were be pooled to assess the level of exercise adherence post-operatively. Definitions of exercise adherence and types of measurements used were presented using summary tables.

\section{Intervention reporting}

Completeness of intervention reporting was measured as a percentage of intervention completeness, assessing the number of items in the CERT checklist that were 
included within the study. We reported the median and interquartile range to describe the number of reported items within each RCT. A total score for the CERT, for the intervention and control group of each study, was calculated and reported as mean and standard deviation. Additionally, a description of each item that was not met from the CERT for all exercise interventions in each study was provided in the text analysis. Differences between the number of items met on the CERT between the intervention and control groups were assessed using a paired t-test, with a significance level of 0.05 . Of the studies that contained two intervention groups and one control, [18-24] an average of the CERT total score for the intervention was used to conduct the paired t-test. Studies that did not include a control group were excluded from the analysis. Given that the CERT checklist was developed in 2016 and there was no date limit for inclusion of studies in this review, we conducted an independent $\mathrm{t}$-test to assess differences in CERT score prior to and proceeding the publication of the checklist. Cochrane risk of bias was described qualitatively, with studies being labelled with high, low, or unclear risk of bias. STATA IC 15 was used to perform the statistical analysis (t-test), at an alpha level of 0.05 [25].

\section{Results}

\section{Study selection}

A total of 7858 studies were identified through database searches and a total of 374 through a hand search of reference lists (Fig. 1). Thus, a total of 5513 titles and abstracts were screened after removal of duplicates. Of these studies, 243 citations were considered potentially relevant and were kept for full-text review. A total of 131 citations were excluded because they did not fulfil the inclusion criteria (See Additional file 4: Appendix D for full list of excluded studies with reasons for exclusion). Reasons for exclusion included: 1) Abstract/Title only (e.g., conference proceedings), 2) Duplications, 3) Continuous Passive Motion, 4) Study not yet published, 5) Study terminated, 6) Wrong intervention, study design, or patient population, and 7) Unable to locate/ translate study. Finally, 112 RCTs were included in this review [18-24, 26-130].

\section{General characteristics}

The 112 RCTs consisted of a total of 120 intervention groups (more than one treatment arm in some studies) and 112 control groups. These RCTs were conducted in 28 different countries. The top countries included the United States of America (18.8\%, $n=21)$, Australia $(8.9 \%, n=10)$, the United Kingdom $(8 \%, n=9)$, and Canada/China/Italy/Germany $(6.3 \%$ respectively, $n=7$ each).

\section{Adherence}

There were $64(57 \%)$ studies that had mentioned exercise adherence within their study $[18,19,22-24,27,29$, $31,33,34,36-38,42-47,50,53,54,58,59,63,65-69$,

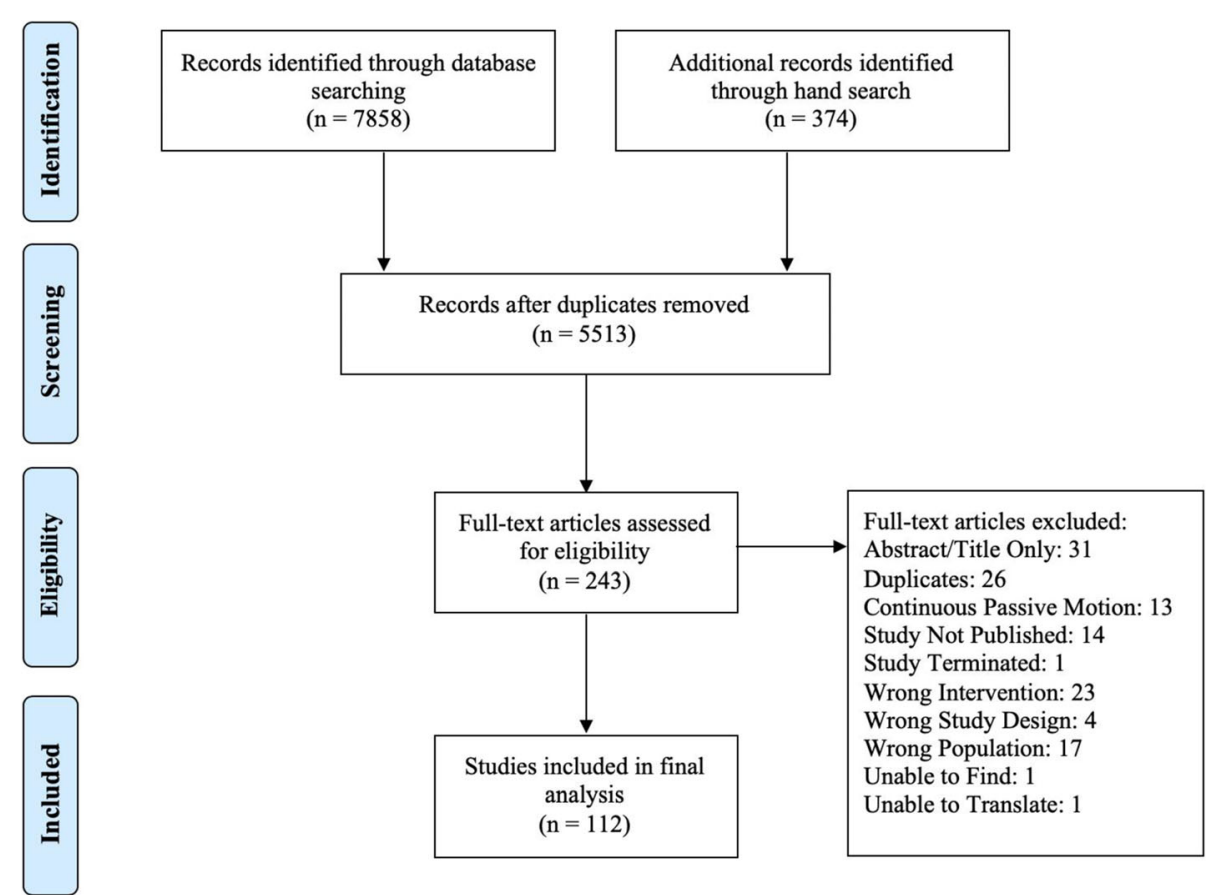

Fig. 1 Flow diagram of study selection process 
$73,74,78,79,82-84,86,90-93,96-100,102-104,107-$ $109,111,112,114,117,118,121,123,126,127,129$, 131]. Of these studies only 41 (65\%) reported sufficient information (e.g. measurement used and outcome) to assess exercise adherence [19, 22, 31, 33, 34, 36, 38, 42-45, $53,58,66-68,74,78,79,82,83,86,90-93,96-98,102-$ $104,107-109,112,114,117,123,126,127]$. There were 15 studies that had a pre-defined cut-off for exercise adherence (see Table 1). There were 6 studies that stated participants would be excluded or discharged from the study, and thus the analysis, if they failed to meet the adherence cut-offs, which is not in line with the recommended intention-to-treatment analysis [18, 19, 38, 74, 123, 129]. There was one study that evaluated exercise adherence as the primary outcome, but did not provide any conceptual framework around the concept of adherence [91].

Of the 69 reported outcome measures to assess adherence, the number of attended sessions (38\%, $n=26 / 69)$, and patient diary $(39 \%, n=27 / 69)$ were the most used (see Table 2). Less commonly used measures of adherence included self-reported patient and clinician questionnaires, activity monitors, computer aided systems (e.g., telehealth app), and duration/intensity of the exercise session. Some studies used multiple measurements when addressing exercise adherence. Adherence was primarily measured during the period of the intervention, which varied from study to study (2-3 day to 8-week intervention periods). Adherence to attended number of sessions ranged from 47 to $100 \%$ in the intervention group $(n=19),[22,31,33,58,67,74,79$, $82,83,86,92,96-98,102,107,108,126]$ and 83 to $100 \%$ for the control group $(n=10)[22,33,74,79,83,86,98$, 107, 108]. Adherence to the assigned exercise sessions as measured using a patient diary ranged from 61 to $110 \%$ in the intervention group $(n=9),[22,31,53,108,109,112$, $123,127]$ and 65.4 to $85 \%$, in the control group $(n=5)$ [22, $31,108,109,112]$. In one study, the authors recommended exercises sessions to be completed $2 \mathrm{x} /$ day, and the intervention group completed more exercises than the recommended dose [112]. Only one study reported on the long term adherence to exercises after the intervention phase was completed (49\% in the intervention group, and 34\% in the control after 12 months) [127].

\section{Completeness of reporting}

There were no significant differences in CERT score based on year of publication (e.g., studies published prior to 2016 compared to those published after the

Table 1 Definitions of exercise adherence in post-operative TKA interventions

\begin{tabular}{|c|c|}
\hline Study & Definition of Adherence/Compliance \\
\hline Akbaba et al. (2016) [18] & "The patients were excluded if they had not completed at least $75 \%$ of the exercise programme." \\
\hline Buhaglar et al. (2017) [19] & $\begin{array}{l}\text { "Adherence for both groups was defined as attendance at no less than } 2 \text { and no more than } 4 \text { outpatient sessions. } \\
\text { Adherence for the inpatient rehabilitation group was further defined as having had a minimum } 7 \text { days of inpatient } \\
\text { rehabilitation." }\end{array}$ \\
\hline $\begin{array}{l}\text { Christiansen et al. (2020) } \\
\text { [45] }\end{array}$ & $\begin{array}{l}\text { "We classified adherence as "achieved" for participants who had } \geq 80 \% \text { of the weekly steps/day goal recorded by the } \\
\text { physical therapist and "not achieved" for those with }<80 \% \text { of the weekly steps/day goals recorded, which is consistent } \\
\text { with the definition of adherence from a pharmacologic perspective." }\end{array}$ \\
\hline Debbi et al. (2019) [47] & "Satisfactory compliance was defined as an average of $>75 \%$ of walking protocol." \\
\hline Fransen et al. (2017) [58] & "Attended the full program of 16 classes." \\
\hline Harmer et al. (2009) [66] & "Attending 8 or more sessions." \\
\hline Johnson et al. (2010) [74] & $\begin{array}{l}\text { "Subjects were required to complete at least } 10 \text { of } 12 \text { scheduled therapy sessions. Subjects were allowed to miss up to } \\
\text { two sessions, but not in the same week, before being discharged from the study." }\end{array}$ \\
\hline Kelly et al. (2016) [78] & "Goal of 2 sessions per week." \\
\hline Kramer et al. (2003) [79] & "Compliance was defined as completion of the home exercises at least 90\% of the time." \\
\hline $\begin{array}{l}\text { Lenguerrand et al. (2019) } \\
\text { [82] }\end{array}$ & "Adherence to the intervention was predefined as attendance at $\geq 4$ sessions." \\
\hline Moffet et al. (2015) [98] & "Subjects who participated in all evaluations and attended at least 75\% of the intervention sessions." \\
\hline Ko et al. (2013) [22] & "Intervention group attended > 9 sessions; the control attended 2 sessions." \\
\hline Paxton et al. (2018) [103] & $\begin{array}{l}\text { "The adherence rate (in the physical activity feedback group) cutoff of greater than } 90 \% \text { was assessed as the ratio of the } \\
\text { number of weeks that the Fitbit wearable sensor and tablet application were used over the total number of weeks. Use } \\
\text { of the Fitbit sensor was assessed by noting daily wear time ( } \geq 12 \mathrm{~h} \text { representing a valid day). Dose goal cutoff of } 80 \% \\
\text { was assessed as the ratio of the total number of participants achieving their goals over the total number of participants, } \\
\text { for each week of the intervention." }\end{array}$ \\
\hline $\begin{array}{l}\text { Trudelle-Jackson et al. } \\
\text { (2020) [123] }\end{array}$ & $\begin{array}{l}\text { "Participants were considered } 100 \% \text { compliant if they exercised } 3 \text { to } 4 \text { times per week for } 8 \text { weeks (intervention group } \\
\text { only). A minimum requirement of } 50 \% \text { compliance with the high-velocity exercise training program was necessary to re- } \\
\text { main in the study." }\end{array}$ \\
\hline Yousefian et al. (2017) [129] & "Patients not attending 100\% of their therapeutic sessions were also excluded from the study." \\
\hline
\end{tabular}


Table 2 Frequency and percentage of commonly measured outcomes of exercise adherence

\begin{tabular}{ll}
\hline Exercise Adherence Outcome Measure & Frequency (Percentage) \\
\hline Activity Monitor & $3(4.35 \%)$ \\
Computer App & $3(4.35 \%)$ \\
Patient Diary & $27(39 \%)$ \\
Number of Attended Sessions & $26(37.68 \%)$ \\
Goal Attainment & $1(1.45 \%)$ \\
Session Duration & $4(5.80 \%)$ \\
Patient Reported Questionnaire & $3(4.35 \%)$ \\
Practitioner Reported Questionnaire & $2(2.90 \%)$
\end{tabular}

development of the questionnaire), both in the intervention $\left(\mathrm{T}_{110}=1.68, p<0.1\right.$, mean difference $1.12, \mathrm{CI}_{95 \%}$ $[-0.2,2.44)$ and control $\left(\mathrm{T}_{106}=0.47, p<0.6\right.$, mean difference $0.34, \mathrm{CI}_{95 \%}[-1.08,1.75)$ groups. There were no RCTs that fulfilled all 16 items (total score of 19) of the CERT (See Additional file 5: Appendix E for the completion of the CERT for each included study). There were 18 RCTs that reported at least 14 (74\%) items intervention group, $[19,22,31,38,45,58,74,77,78$, $82,86,90,97,107,117,123,127]$ and 9 RCTs in the control group [19, 22, 31, 38, 45, 74, 78, 108, 117]. Frequency and percentage of adequately reported CERT items are presented in Table 2. The mean (standard deviation) of adequately reported items in the intervention group was 9.4 (3.5), ranging from 1 to 16 items, which was significantly higher as compared to the control group, 8.0 (3.7), ranging from 1 to17 items, $\mathrm{T}_{107}=5.56, p<0.0001$, mean difference $1.45, \mathrm{CI}_{95 \%}[0.94,1.97]$.

The most reported items in the CERT, in both the intervention and control groups, included mode of delivery (Item 2: Group or individual; Item 3: Supervised or unsupervised), setting (Item 12), and if the intervention was tailored or not (Item 14a), ranging from 80 to $99 \%$. All the other items included in the CERT were not fulfilled on at least $60 \%$ of the RCTs. See Table 3 for more detailed information on the reporting of CERT items.

Table 3 Frequency and percentage of adequately reported CERT items in the intervention and control groups of post-operative TKA studies

\begin{tabular}{|c|c|c|}
\hline \multirow[t]{2}{*}{ CERT Item } & \multirow{2}{*}{$\begin{array}{l}\text { Intervention } \\
(n=120) \\
\text { Frequency }(\%)\end{array}$} & \multirow{2}{*}{$\begin{array}{l}\text { Control }(n=112) \\
\text { Frequency (\%) }\end{array}$} \\
\hline & & \\
\hline Item 1: Exercise Equipment & $69(58 \%)$ & $32(31 \%)$ \\
\hline Item 2: Provider Qualifications & $10(8 \%)$ & $7(6 \%)$ \\
\hline Item 3: Individual/Group Delivery & $114(95 \%)$ & $95(87 \%)$ \\
\hline Item 4: Supervised/Unsupervised & 119 (99\%) & $101(93 \%)$ \\
\hline Item 5: Exercise Adherence & $43(35 \%)$ & $29(27 \%)$ \\
\hline Item 6: Motivation & $39(33 \%)$ & $24(22 \%)$ \\
\hline Item 7a: Exercise Progression Decision & $63(53 \%)$ & $38(35 \%)$ \\
\hline Item 7b: Exercise Progression Description & $49(41 \%)$ & $29(28 \%)$ \\
\hline Item 8: Description of Exercise & $69(58 \%)$ & $46(43 \%)$ \\
\hline Item 9: Home Program Component & $62(52 \%)$ & $50(46 \%)$ \\
\hline Item 10: Non-Exercise Component & $63(52 \%)$ & $53(49 \%)$ \\
\hline Item 11: Adverse Events & $54(45 \%)$ & $49(45 \%)$ \\
\hline Item 12: Setting of Intervention & $110(92 \%)$ & $96(89 \%)$ \\
\hline Item 13: Dosage Total & $45(38 \%)$ & $32(30 \%)$ \\
\hline Sets & $52(43 \%)$ & $41(38 \%)$ \\
\hline Reps & $50(42 \%)$ & 37 (35\%) \\
\hline Duration & $79(65 \%)$ & $57(53 \%)$ \\
\hline Intensity & $48(40 \%)$ & $29(27 \%)$ \\
\hline Item 14a: Tailored/Generic & $106(88 \%)$ & 87 (81\%) \\
\hline Item 14b: Description of Tailoring & $9(23 \%)$ & $5(16 \%)$ \\
\hline Item 15: Starting Level of Intervention & $50(42 \%)$ & $35(33 \%)$ \\
\hline Item 16a: Intervention Delivered as Planned & $40(33 \%)$ & $29(27 \%)$ \\
\hline Item 16b: Fidelity & 25 (21\%) & 23 (21\%) \\
\hline
\end{tabular}




\section{Cochrane risk of Bias assessment}

The majority of RCTs included in this review were of poor quality with 16 studies with low risk of bias across all domains, 72 with high risk of bias for one or more of the key domains, and 24 with unclear risk of bias for one or more of the key domains (See Additional file 6: Appendix $\mathrm{F}$ for detailed risk of bias assessment). Figure 2 provides a summary of risk of bias judgements for each domain across each all studies.

\section{Discussion}

The RCTs included in this study poorly reported exercise adherence, as well as description of the postoperative TKA rehabilitation intervention. In general, RCTs were of poor quality, with the majority of studies having high or unclear risk of bias across one or more key domains. Similarly, the overall reporting of the CERT items was very poor within the RCTs. While neither intervention was adequately reported, the control group was more likely to be underreported as compared to the intervention group, despite both containing exercise components. These findings are fairly consistent with recent literature which suggests less than one fifth of studies adequately report exercise interventions in other musculoskeletal conditions, [132] educational interventions, [133] as well as in the intensive care unit [134]. Additionally, previous studies have shown that reporting of interventions has improved with time in other health conditions [132]; however, the results of this study show no differences in reporting of interventions over time. This suggests a significant proportion of researchers assessing post-operative TKA interventions have not adapted the newer recommendations for reporting of interventions.

Of the studies that mentioned exercise adherence, very few provided a definition of adherence in the context of their study. A compounding problem, however, is that some that defined adherence included pre-defined cutoffs, [18, 19, 38, 74, 123, 129] in which participants would be excluded from the study and analysis if they did not meet them. These cut-offs were different in each study and were not based on any scientific rationale for assessing adherence. As such, intent-to-treat analysis was not used, which may overestimate the effectiveness of the intervention. Authors should properly define exercise adherence and treat adherence as a continuous measure such that statistical procedures may address the issue of nonadherence.

One interesting, but not surprising, finding of this review is that the terms adherence and compliance were used interchangeably. Compliance and adherence, however, are inherently different constructs. Compliance refers to "the extent to which the patient's behaviour matches the prescriber's recommendations." [135] While adherence, according to the WHO, refers to "the extent to which a person's behaviour, taking medication, following a diet, and/or executing lifestyle changes, corresponds with agreed recommendations from a health care provider." [135] In this case, adherence refers to a process in which the agreed upon treatment is discussed with the patient. In this way, the patient is not the only person responsible for non-adherence but places an onus on the clinician as well. A recent systematic review of the validity, reliability, and acceptability of exercise adherence measures provided an extension to the WHO definition: "The extent to which individuals undertake prescribed behaviour accurately and at the agreed frequency, intensity and duration." [9] It is clear, however, that there is no agreed upon definition of exercise adherence and the most commonly used definition by the WHO lacks specific concepts (e.g.,

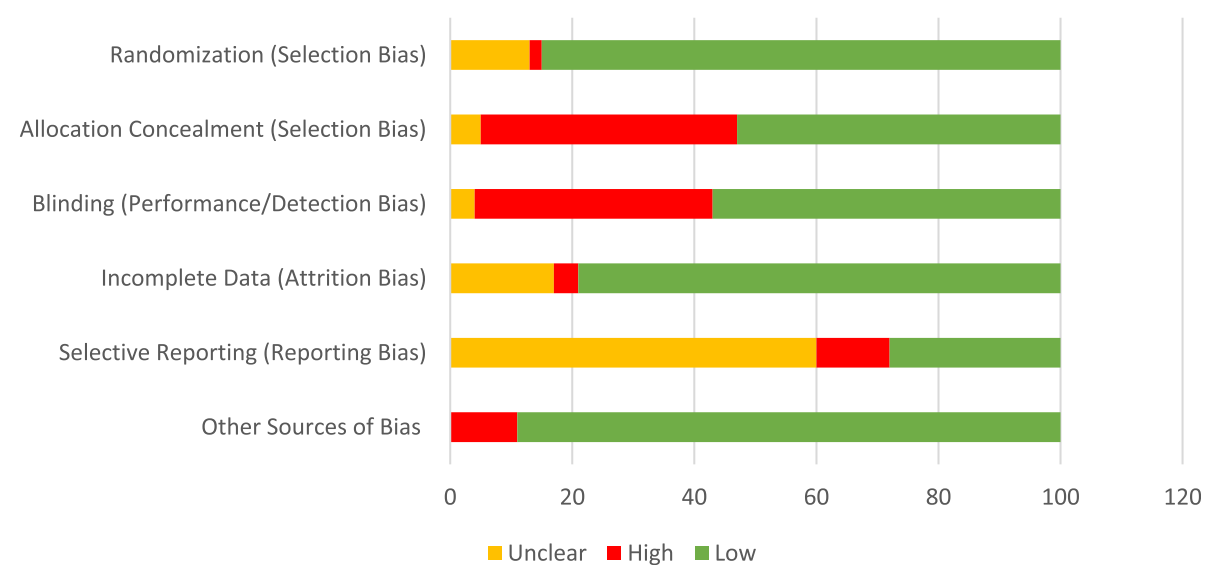

Fig. 2 Risk of Bias. The authors' judgements regarding each domain of the Cochrane Risk of Bias Assessment Tool presented as percentages across all studies 
frequency, intensity, accuracy, etc.), which are important in adherence to exercise [136].

Outcome measures used to assess adherence varied between studies including subjective (e.g., diary, selfreported patient/practitioner questionnaire) and objective measures (e.g., accelerometers, number of attended sessions). Exercise adherence was commonly measured as the number of supervised exercise sessions and self-reported exercise diary. These methods, however, have been reported to have poor validity and reliability [9]. The inconsistency in measurements used to assess adherence limits the ability to draw conclusions regarding accuracy and compare between studies [16]. These findings are consistent with previous literature that suggests lack of reporting of adherence in exercise interventions [137]. Lack of proper reporting of adherence may lead to underestimation of treatment effects, in that, participants may not be improving after an exercise intervention due to lack of adherence, rather than an ineffective intervention, and will limit clinical application and proper understanding of the burden of the intervention on the patient. Future studies should aim to validate existing measures of exercise adherence that can be used to accurately assess this construct within a clinical trial. It is recommended that authors use valid and reliable outcome measures of exercise adherence across all study treatment arms.

Poor reporting for post-operative TKA exercise interventions is particularly concerning as it limits reproducibility of research, but more importantly, it limits translation into clinical practice. The majority of RCTs included in this study failed to report more than $70 \%$ of the CERT items in both the intervention and control group. This is consistent with recent literature that assessed reporting interventions for LBP [132]. In particular, description of the exercises, dosage, progression of exercise, adverse events, content of home program/non-exercise components, and fidelity were not well reported. These items may directly relate to exercise adherence, and thereby, influence uptake of exercise in the long-term. Based on the results of this study, it is unclear if authors did not include these vital components within their interventions, or simply failed to report them. Future studies should aim to report all recommended items within an intervention reporting checklist and provide rationale if items were not included within their intervention.

Without adequate information of how interventions are developed or implemented, studies recommending rehabilitation for post-operative TKA should be interpreted with caution. Inadequate reporting of specific rehabilitation procedures may lead to improper clinical application, leading to potential harm [132]. These items are particularly important in intervention reporting to reduce bias in implementation, as well as standardization for future studies or clinical replications. Poor reporting can be, in part, attributed to the complexity of rehabilitation interventions [138] leading to difficulty of standardization [139].

\section{Limitations and strengths}

This study had several limitations, first publication bias may influence adherence results as studies that have poor adherence are generally less likely to be published [140]. The purpose of this study was to evaluate the reporting of intervention within primary research articles, and as such, protocol studies were excluded from this review. Some research articles describe their interventions within their published protocols, and this may have been missed in the overall reporting of this study. Since the purpose of this scoping review was to assess the completeness of intervention reporting, there was no considerations of effectiveness of each intervention. The strengths of this study relate to the use of a framework that provides transparency and replicability. Additionally, we used multiple databases that allowed us to capture most studies that assessed post-op TKA rehabilitation. This study also looked at both the control and intervention groups separately using a validated reporting tool as well as the validated Cochrane Risk of Bias assessment tool, which ensures replicability as well as a comprehensive analysis of the current literature in post-op TKA rehabilitation.

\section{Conclusion}

In conclusion, exercise adherence is poorly reported within studies of post-operative TKA rehabilitation. The majority of studies measured exercise adherence through the use of patient diaries, or number of attended session. Further, very few studies provided a defintition of adherence. A such, future studies should aim to identify accurate and reliable measures of adherence, and authors should include an exercise reporting tool when planning/implementing exercise interventions as well as provide a clear definition of exercise adherence. In general, the completeness of reporting components of both the intervention and control groups was very poor. Proper reporting will allow for smoother translation of research into clinical practice as well as better quality and reproducibility of research.

\section{Abbreviations}

TKA: Total knee arthroplasty; RCT: Randomized Controlled Trial; CERT: Consensus on Exercise Reporting Template 


\section{Supplementary Information}

The online version contains supplementary material available at https://doi. org/10.1186/s12891-021-04460-w.

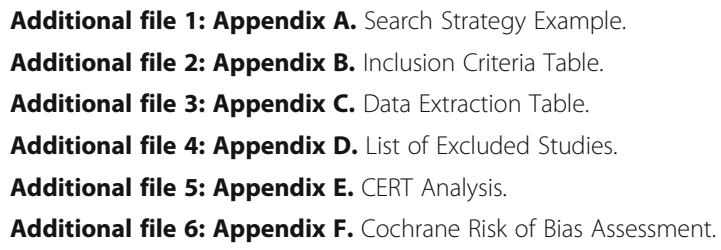

\section{Acknowledgements}

Not applicable.

\section{Authors' contributions}

NB developed the research questions, designed the studies, collected and analyzed the data, and wrote the initial drafts. LHC and NB screened and extracted the data. LM helped to refine and guide the research questions and with the analysis of the study. LC, JR and LM helped with interpretation and revision/editing for the manuscript. The author(s) read and approved the final manuscript.

\section{Funding}

The authors declare no funding sources for the completion of this study.

\section{Availability of data and materials}

The datasets used and/or analysed during the current study may be extracted from the original articles or will be made available from the corresponding author on upon request.

\section{Declarations}

Ethics approval and consent to participate

Not applicable.

\section{Consent for publication}

Not applicable.

\section{Competing interests}

The authors declare that they have no competing interests.

Received: 8 February 2021 Accepted: 8 June 2021

Published online: 30 June 2021

\section{References}

1. Westby MD, Brittain A, Backman CL. Expert consensus on best practices for post-acute rehabilitation after total hip and knee arthroplasty: a Canada and United States Delphi study. Arthritis Care Res. 2014;66(3):411-23. https://doi.org/10.1002/acr.22164.

2. Umehara T, Tanaka R. Effective exercise intervention period for improving body function or activity in patients with knee osteoarthritis undergoing total knee arthroplasty: a systematic review and meta-analysis. Braz J Phys Ther. 2018;22(4):265-75. https://doi.org/10.1016/j.bjpt.2017.10.005.

3. Mark-Christensen T, Juhl C, Thorborg K, Bandholm T: Is physical rehabilitation superior to no physical rehabilitation following total knee arthroplasty? A systematic review and meta-analysis. medRxiv 2020.

4. Pozzi F, Snyder-Mackler L, Zeni J. Physical exercise after knee arthroplasty: a systematic review of controlled trials. Eur J Phys Rehabil Med. 2013;49(6): 877-92.

5. Artz N, Elvers KT, Lowe CM, Sackley C, Jepson P, Beswick AD. Effectiveness of physiotherapy exercise following total knee replacement: systematic review and meta-analysis. BMC Musculoskelet Disord. 2015;16(1):15. https:// doi.org/10.1186/s12891-015-0469-6.

6. Ardali G. A daily adjustable progressive resistance exercise protocol and functional training to increase quadriceps muscle strength and functional performance in an elderly homebound patient following a total knee arthroplasty. Physiother Theory Pract. 2014;30(4):287-97. https://doi.org/1 0.3109/09593985.2013.868064.
7. Meier W, Mizner R, Marcus R, Dibble L, Peters C, Lastayo PC. Total knee arthroplasty: muscle impairments, functional limitations, and recommended rehabilitation approaches. J Orthop Sports Phys Ther. 2008;38(5):246-56. https://doi.org/10.2519/jospt.2008.2715.

8. Mistry JB, Elmallah RD, Bhave A, Chughtai M, Cherian JJ, McGinn T, et al. Rehabilitative guidelines after total knee arthroplasty: a review. J Knee Surg. 2016;29(03):201-17. https://doi.org/10.1055/s-0036-1579670.

9. Frost R, Levati S, McClurg D, Brady M, Williams B. What adherence measures should be used in trials of home-based rehabilitation interventions? A systematic review of the validity, reliability, and acceptability of measures. Arch Phys Med Rehabil. 2017;98(6):1241-1256.e1245.

10. Levac D, Colquhoun H, O'Brien KK. Scoping studies: advancing the methodology. Implement Sci. 2010;5(1):69. https://doi.org/10.1186/17485908-5-69.

11. Page MJ, Moher D. Evaluations of the uptake and impact of the preferred reporting items for systematic reviews and Meta-analyses (PRISMA) statement and extensions: a scoping review. Syst Rev. 2017:6(1):1-14.

12. Arksey H, O'Malley L. Scoping studies: towards a methodological framework. Int J Soc Res Methodol. 2005;8(1):19-32. https://doi.org/10.1080/1364557032 000119616.

13. Gill SD, McBurney H. Does exercise reduce pain and improve physical function before hip or knee replacement surgery? A systematic review and meta-analysis of randomized controlled trials. Arch Phys Med Rehabil. 2013; 94(1):164-76. https://doi.org/10.1016/j.apmr.2012.08.211.

14. Higgins JP, Altman DG, Gøtzsche $P C$, Jüni $P$, Moher D, Oxman $A D$ et al. The Cochrane Collaboration's tool for assessing risk of bias in randomised trials. BMJ. 2011;343(oct18 2):d5928. https://doi.org/10.113 6/bmj.d5928.

15. Slade SC, Dionne CE, Underwood M, Buchbinder R, Beck B, Bennell K, et al. Consensus on exercise reporting template (CERT): modified Delphi study. Phys Ther. 2016;96(10):1514-24. https://doi.org/10.2522/ptj.20150668.

16. Slade SC, Dionne CE, Underwood M, Buchbinder R. Consensus on exercise reporting template (CERT): explanation and elaboration statement. $\mathrm{Br}$ J Sports Med. 2016;50(23):1428-37. https://doi.org/10.1136/bjsports-2016096651

17. Slade SC, Finnegan S, Dionne CE, Underwood M, Buchbinder R. The consensus on exercise reporting template (CERT) applied to exercise interventions in musculoskeletal trials demonstrated good rater agreement and incomplete reporting. J Clin Epidemiol. 2018;103:120-30. https://doi. org/10.1016/j.jclinepi.2018.07.009.

18. Akbaba Y, Yeldan I, Guney N, Ozdincler A, Akbaba YA, Ozdincler AR. Intensive supervision of rehabilitation programme improves balance and functionality in the short term after bilateral total knee arthroplasty. Knee Surg Sports Traumatol Arthrosc. 2016;24(1):26-33. https://doi.org/10.1007/ s00167-014-3179-y.

19. Buhaglar M, Naylor J, Harris I, Xuan W, Kohler F, Wright R, et al. Effect of inpatient rehabilitation vs a monitored home-base program on mobility in patients with total knee arthroplasty: the $\mathrm{HIHO}$ randomized clinical trial. J Am Med Assoc. 2017;317(10):1037-46. https://doi.org/10.1001/jama.201 7.1224

20. Chen H, Du SS, Fan $\sqcup$, Jiang J, Liang XY, Zhen P, et al. Effects of combination therapy on the movement function of lower extremity after total knee arthroplasty in the elderly. [Chinese]. Chinese J Tissue Eng Res. 2017;21(31):4939-44

21. Fleischman AN, Crizer MP, Tarabichi M, Smith S, Rothman RH, Lonner JH, et al. 2018 John N. Insall award: recovery of knee flexion with unsupervised home exercise is not inferior to outpatient physical therapy after TKA: a randomized trial. Clin Orthop Relat Res. 2019;477(1):60-9.

22. Ko V, Naylor J, Harris I, Crosbie J, Yeo A, Mittal R. One-to-one therapy is not superior to group or home-based therapy after total knee arthroplasty: a randomized, superiority trial. J Bone Joint Surg (Am Vol). 2013;95(21):1942-9. https://doi.org/10.2106/JBJS.L.00964.

23. Piva SR, Schneider MJ, Moore CG, Catelani MB, Gil AB, Klatt BA, et al. Effectiveness of later-stage exercise programs vs usual medical care on physical function and activity after Total knee replacement: a randomized clinical trial. JAMA Netw Open. 2019;2(2):e190018. https://doi.org/10.1001/ja manetworkopen.2019.0018.

24. Rahmann A, Brauer S, Nitz J. A specific inpatient aquatic physiotherapy program improves strength after total hip or knee replacement surgery: a randomized controlled trial. Arch Phys Med Rehabil. 2009;90(5):745-55. https://doi.org/10.1016/j.apmr.2008.12.011. 
25. StataCorp.: Stata Statistical Software: Release 15. College Station. In. TX StataCorp LLC.; 2017.

26. Alghadir A, Iqbal ZA, Anwer S. Comparison of the effect of pre- and postoperative physical therapy versus post-operative physical therapy alone on pain and recovery of function after total knee arthroplasty. J Phys Ther Sci. 2016;28(10):2754-8. https://doi.org/10.1589/jpts.28.2754.

27. Heikkilä A, Sevander-Kreus N, Häkkinen A, Vuorenmaa M, Salo P, Konsta P, Ylinen J. Effect of total knee replacement surgery and postoperative 12 month home exercise program on gait parameters. Gait Posture. 2017;53:92-7.

28. Aprile I, Rizzo R, Romanini E, De SF, Marsan S, Rinaldi G, et al. Group rehabilitation versus individual rehabilitation following knee and hip replacement: a pilot study with randomized, single-blind, cross-over design. Eur J Phys Rehabil Med. 2011;47(4):551-9.

29. Artz N, Dixon S, Wylde V, Marques E, Beswick AD, Lenguerrand E, et al. Comparison of group-based outpatient physiotherapy with usual care after total knee replacement: a feasibility study for a randomized controlled trial. Clin Rehabil. 2017;31(4):487-99. https://doi.org/10.1177/0269215516642503.

30. Avramidis K, Karachalios T, Popotonasios K, Sacorafas D, Papathanasiades $\mathrm{AA}$, Malizos KN. Does electric stimulation of the vastus medialis muscle influence rehabilitation after total knee replacement? Orthopedics. 2011; 34(3):175-5. https://doi.org/10.3928/01477447-20110124-06.

31. Bade MJ, Struessel T, Dayton M, Foran J, Kim RH, Miner T, et al. Early highintensity versus low-intensity rehabilitation after Total knee arthroplasty: a randomized controlled trial. Arthritis Care Res. 2017;69(9):1360-8. https://doi. org/10.1002/acr.23139.

32. Bellelli G, Buccino G, Bernardini B, Padovani A, Trabucchi M. Action observation treatment improves recovery of postsurgical orthopedic patients: evidence for a top-down effect? Arch Phys Med Rehabil. 2010; 91(10):1489-94. https://doi.org/10.1016/j.apmr.2010.07.013.

33. Bily W, Franz C, Trimmel L, Loefler S, Cvecka J, Zampieri S, et al. Effects of legpress training with moderate vibration on muscle strength, pain, and function after Total knee arthroplasty: a randomized controlled trial. Arch Phys Med Rehabil. 2016;97(6):857-65. https://doi.org/10.1016/j.apmr.2015.12.015.

34. Bini SA, Mahajan J. Clinical outcomes of remote asynchronous telerehabilitation are equivalent to traditional therapy following total knee arthroplasty: a randomized control study. J Telemed Telecare. 2017;23(2): 239-47. https://doi.org/10.1177/1357633X16634518.

35. Bohl DD, Li J, Calkins TE, Darrith B, Edmiston TA, Nam D, et al. Physical Therapy on Postoperative Day Zero Following Total Knee Arthroplasty: A Randomized, Controlled Trial of 394 Patients. J Arthroplast. 2019:34:S173-S177.e171.

36. Brandes M, Wirsik N, Niehoff H, Heimsoth J, Möhring B. Impact of a tailored activity counselling intervention during inpatient rehabilitation after knee and hip arthroplasty - an explorative RCT. BMC Musculoskelet Disord. 2018; 19(1):209. https://doi.org/10.1186/s12891-018-2130-7.

37. Bruun-Olsen V, Heiberg KE, Wahl AK, Mengshoel AM. The immediate and long-term effects of a walking-skill program compared to usual physiotherapy care in patients who have undergone total knee arthroplasty (TKA): a randomized controlled trial. Disabil Rehabil. 2013;35(23):2008-15. https://doi.org/10.3109/09638288.2013.770084.

38. Bugbee WD, Pulido PA, Goldberg T, D'Lima DD. Use of an anti-gravity treadmill for early postoperative rehabilitation after Total knee replacement: a pilot study to determine safety and feasibility. Am J Orthop (Belle Mead NJ). 2016:45(4):E167-73.

39. Bulthuis Y, Drossaers-Bakker KW, Taal E, Rasker J, Oostveen J, van't Pad BP, et al. Arthritis patients show long-term benefits from 3 weeks intensive exercise training directly following hospital discharge. Rheumatology. 2007; 46(11):1712-7. https://doi.org/10.1093/rheumatology/kem236.

40. Cai L, Gao H, Xu H, Wang Y, Lyu P, Liu Y. Does a program based on cognitive behavioral therapy affect Kinesiophobia in patients following Total knee arthroplasty? A randomized, controlled trial with a 6-month follow-up. J Arthroplast. 2018;33(3):704-10. https://doi.org/10.1016/j.arth.2017.10.035.

41. Cai LB, Liu YJ, Zhao H, Xu HP, Gao HH, Dong YZ. Cognitive behavior therapy alleviates kinesiophobia after total knee arthroplasty. [Chinese]. Chinese J Tissue Eng Res. 2017;21(23):3658-63.

42. Campbell KJ, Louie PK, Bohl DD, Edmiston T, Mikhail C, Li J, et al. A novel, automated text-messaging system is effective in patients undergoing Total joint arthroplasty. J Bone Joint Surg (Am Vol). 2019;101(2):145-51. https:// doi.org/10.2106/JBJS.17.01505.

43. Chen M, Li P, Lin F. Influence of structured telephone follow-up on patient compliance with rehabilitation after total knee arthroplasty. Patient Prefer Adherence. 2016;10:257-64. https://doi.org/10.2147/PPA.S102156.
44. Christiansen C, Bade M, Davidson B, Dayton M, Stevens-Lapsley J. Effects of weight-bearing biofeedback training on functional movement patterns following total knee arthroplasty: a randomized controlled trial. J Orthop Sports Phys Ther. 2015;45(9):647-55. https://doi.org/10.2519/jospt.2015.5593.

45. Christiansen MB, Thoma LM, Master H, Voinier D, Schmitt LA, Ziegler ML, et al. Feasibility and preliminary outcomes of a physical therapistadministered physical activity intervention after Total knee replacement. Arthritis Care Res. 2020;72(5):661-8. https://doi.org/10.1002/acr.23882.

46. De Fine M, Traina F, Giavaresi G, Leo E, Sanzarello I, Perna F, et al. Effect of different postoperative flexion regimes on the outcomes of total knee arthroplasty: randomized controlled trial. Knee Surg Sports Traumatol Arthrosc. 2017;25(9):2972-7. https://doi.org/10.1007/s00167-016-4119-9.

47. Debbi EM, Bernfeld B, Herman A, Salai M, Laufer Y, Wolf A, et al. A biomechanical foot-worn device improves Total knee arthroplasty outcomes. J Arthroplast. 2019;34(1):47-55. https://doi.org/10.1016/j.arth.2018. 09.077 .

48. Demircioglu DT, Paker N, Erbil E, Bugdayci D, Emre TY. The effect of neuromuscular electrical stimulation on functional status and quality of life after knee arthroplasty: a randomized controlled study. J Phys Ther Sci. 2015;27(8):2501-6. https://doi.org/10.1589/jpts.27.2501.

49. den Hertog A, Gliesche K, Timm J, Mühlbauer B, Zebrowski S. Pathwaycontrolled fast-track rehabilitation after total knee arthroplasty: a randomized prospective clinical study evaluating the recovery pattern, drug consumption, and length of stay. Arch Orthop Trauma Surg. 2012;132(8): 1153-63. https://doi.org/10.1007/s00402-012-1528-1.

50. Doerfler D, Gurney B, Mermier C, Rauh M, Black L, Andrews R. High-velocity quadriceps exercises compared to slow-velocity quadriceps exercises following Total knee arthroplasty: a randomized clinical study. J Geriatr Phys Ther. 2016;39(4):147-58. https://doi.org/10.1519/JPT.0000000000000071.

51. Donec $V$, Krisciunas $A$. The effectiveness of Kinesio taping after total knee replacement in early postoperative rehabilitation period. A randomized controlled trial. Eur J Phys Rehabil Med. 2014;50(4):363-71.

52. Ebert JR, Joss B, Jardine B, Wood DJ. Randomized trial investigating the efficacy of manual lymphatic drainage to improve early outcome after Total knee arthroplasty. Arch Phys Med Rehabil. 2013;94(11):2103-11. https://doi. org/10.1016/j.apmr.2013.06.009.

53. Eichler S, Salzwedel A, Rabe S, Mueller S, Mayer F, Wochatz M, et al. The effectiveness of Telerehabilitation as a supplement to rehabilitation in patients after Total knee or hip replacement: randomized controlled trial. JMIR Rehabil Assist Technol. 2019;6(2):e14236. https://doi.org/10.2196/14236.

54. Eisermann U, Haase I, Kladny B. Computer-aided multimedia training in orthopedic rehabilitation. Am J Phys Med Rehabil. 2004;83(9):670-80. https://doi.org/10.1097/01.PHM.0000137307.44173.5D.

55. Evgeniadis G, Beneka A, Malliou P, Mavromoustakos S, Godolias G. Effects of pre- or postoperative therapeutic exercise on the quality of life, before and after total knee arthroplasty for osteoarthritis. J Back Musculoskelet Rehabil. 2008;21(3):161-9. https://doi.org/10.3233/BMR-2008-21303.

56. Ficklscherer A, Stapf J, Meissner KM, Niethammer T, Lahner M, Wagenhauser $\mathrm{M}$, et al. Testing the feasibility and safety of the Nintendo Wii gaming console in orthopedic rehabilitation: a pilot randomized controlled study. Arch Med Sci. 2016;12(6):1273-8. https://doi.org/10.5114/aoms.2016.59722.

57. Fortuno Godes J, Martin Baranera M, Kadar García E, Redondo Parra I, Gallardo Perez B. Decrease in pain and weight loss during physiotherapy treatment in patients operated on for knee prosthesis. Fisioterapia. 2010; 32(1):11-6.

58. Fransen M, Nairn L, Bridgett L, Crosbie J, March L, Parker D, et al. Post-acute rehabilitation after Total knee replacement: a multicenter randomized clinical trial comparing long-term outcomes. Arthritis Care Res. 2017;69(2): 192-200. https://doi.org/10.1002/acr.23117.

59. Frost $H, L a m b ~ S$, Robertson $S$. A randomized controlled trial of exercise to improve mobility and function after elective knee arthroplasty. Feasibility, results and methodological difficulties. Clin Rehabil. 2002;16(2):200-9. https://doi.org/10.1191/0269215502cr483oa.

60. Fung V, Ho A, Shaffer J, Chung E, Gomez M. Use of Nintendo Wii fit (TM) in the rehabilitation of outpatients following total knee replacement: a preliminary randomised controlled trial. Physiotherapy (London). 2012:98(3): 183-8. https://doi.org/10.1016/j.physio.2012.04.001.

61. Gianola S, Stucovitz E, Castellini G, Mascali M, Vanni F, Tramacere I, et al. Effects of early virtual reality-based rehabilitation in patients with total knee arthroplasty: a randomized controlled trial. Medicine. 2020;99(7):e19136. https://doi.org/10.1097/MD.0000000000019136. 
62. Giaquinto S, Ciotola E, Dall'Armi V, Margutti F. Hydrotherapy after total knee arthroplasty. A follow-up study. Arch Gerontol Geriatr. 2010;51(1):59-63. https://doi.org/10.1016/j.archger.2009.07.007.

63. Han AS, Nairn L, Harmer AR, Crosbie J, March L, Parker D, et al. Early rehabilitation after total knee replacement surgery: a multicenter, noninferiority, randomized clinical trial comparing a home exercise program with usual outpatient care. Arthritis Care Res. 2015;67(2):196-202. https://doi. org/10.1002/acr.22457.

64. Hardt S, Schulz MRG, Pfitzner T, Wassilew G, Horstmann H, Liodakis E, et al. Improved early outcome after TKA through an app-based active muscle training programme-a randomized-controlled trial. Knee Surg Sports Traumatol Arthrosc. 2018;26(11):3429-37. https://doi.org/10.1007/s00167-01 8-4918-2.

65. Harikesavan K, Chakravarty RD, Maiya AG, Hegde SP, YS S. Hip abductor strengthening improves physical function following Total knee replacement: one-year follow-up of a randomized pilot study. Open Rheumatol J. 2017; 11(1):30-42. https://doi.org/10.2174/1874312901711010030.

66. Harmer AR, Naylor JM, Crosbie J, Russell T. Land-based versus waterbased rehabilitation following total knee replacement: a randomized, single-blind trial. Arthritis Rheum. 2009;61(2):184-91. https://doi.org/10.1 002/art.24420

67. Hepperger C, Gföller P, Hoser C, Ulmer H, Fischer F, Schobersberger W, et al. The effects of a 3-month controlled hiking programme on the functional abilities of patients following total knee arthroplasty: a prospective, randomized trial. Knee Surg Sports Traumatol Arthrosc. 2017;25(11):3387-95. https://doi.org/10.1007/s00167-016-4299-3.

68. Hoorntje A, Witjes S, Kuijer P, Bussmann JBJ, Horemans HLD, Kerkhoffs G, et al. Does activity-based rehabilitation with goal attainment scaling increase physical activity among younger knee arthroplasty patients? Results from the randomized controlled ACTION trial. J Arthroplast. 2020;35(3):70611. https://doi.org/10.1016/j.arth.2019.10.028.

69. Husby $\mathrm{V}$, Foss $\mathrm{O}$, Husby O, Winther $\mathrm{S}$. Randomized controlled trial of maximal strength training vs. standard rehabilitation following total knee arthroplasty. Eur J Phys Rehabil Med. 2018;54(3):371-9. https://doi.org/10.23 736/S1973-9087.17.04712-8

70. Iwakiri K, Ohta Y, Shibata Y, Minoda Y, Kobayashi A, Nakamura H. Initiating range of motion exercises within 24 hours following total knee arthroplasty affects the reduction of postoperative pain: a randomized controlled trial. Asia Pac J Sports Med Arthrosc Rehabil Technol. 2020;21:11-6. https://doi. org/10.1016/j.asmart.2020.03.003.

71. Jakobsen TL, Kehlet H, Husted H, Petersen J, Bandholm T. Early progressive strength training to enhance recovery after fast-track total knee arthroplasty: a randomized controlled trial. Arthritis Care Res. 2014;66(12):1856-66. https://doi.org/10.1002/acr.22405.

72. Jin C, Feng $Y$, Ni Y, Shan Z. Virtual reality intervention in postoperative rehabilitation after total knee arthroplasty: a prospective and randomized controlled clinical trial. Int J Clin Exp Med. 2018;11(6):6119-24.

73. Jogi P, Overend TJ, Spaulding SJ, Zecevic A, Kramer JF. Effectiveness of balance exercises in the acute post-operative phase following total hip and knee arthroplasty: A randomized clinical trial. SAGE Open Medicine. 2015;3: no pagination

74. Johnson AW, Myrer JW, Hunter I, Feland JB, Hopkins JT, Draper DO, et al. Whole-body vibration strengthening compared to traditional strengthening during physical therapy in individuals with total knee arthroplasty. Physiother Theory Pract. 2010;26(4):215-25. https://doi.org/10.3109/09593 980902967196.

75. Ju CJ, Zhou X, Dong CC, Lin LQ, Liu HN, Hou Y. Clinical observation of warm moxibustion therapy to improve quadriceps weakness after total knee arthroplasty. Zhongguo Zhen Jiu. 2019;39(3):276-9. https://doi.org/1 0.13703/j.0255-2930.2019.03.014.

76. Karaman A, Yuksel I, Kinikli Gl, Caglar O. Do Pilates-based exercises following total knee arthroplasty improve postural control and quality of life? Physiother Theory Pract. 2017;33(4):289-95. https://doi.org/10.1080/09593 985.2017.1289578.

77. Kauppila A, Kyllönen E, Ohtonen P, Hämäläinen M, Mikkonen P, Laine V, et al. Multidisciplinary rehabilitation after primary total knee arthroplasty: a randomized controlled study of its effects on functional capacity and quality of life. Clin Rehabil. 2010;24(5):398-411. https://doi.org/10.1177/02 69215509346089.

78. Kelly MA, Finley M, Lichtman SW, Hyland MR, Edeer AO. Comparative analysis of high-velocity versus low-velocity exercise on outcomes after
Total knee arthroplasty: a randomized clinical trial. J Geriatr Phys Ther. 2016; 39(4):178-89. https://doi.org/10.1519/JPT.0000000000000070.

79. Kramer JF, Speechley M, Bourne R, Rorabeck C, Vaz M. Comparison of clinicand home-based rehabilitation programs after total knee arthroplasty. Clin Orthop Relat Res. 2003;410:225-34. https://doi.org/10.1097/01.blo.0000063 600.67412 .11 .

80. Larsen K, Sørensen OG, Hansen TB, Thomsen PB, Søballe K. Accelerated perioperative care and rehabilitation intervention for hip and knee replacement is effective: a randomized clinical trial involving 87 patients with 3 months of follow-up. Acta Orthop. 2008;79(2):149-59. https://doi. org/10.1080/17453670710014923.

81. Lee JY, Kim JH, Lee BH. Effect of Dynamic Balance Exercises Based on Visual Feedback on Physical Function, Balance Ability, and Depression in Women after Bilateral Total Knee Arthroplasty: A Randomized Controlled Trial. Int J Environ Res Public Health. 2020;17(9):3203.

82. Lenguerrand E, Artz N, Marques E, Sanderson E, Lewis K, Murray J, Parwez T, Bertram W, Beswick AD, Burston A, et al. Effect of group-based outpatient physiotherapy on function after total knee replacement: the ARENA randomised controlled trial. Arthritis Care Res. 2019;72(6):768-77.

83. Lenssen AF, Crijns YHF, Waltje EMH, Van Steyn MJA, Geesink RJT, Van Den Brandt PA, et al. Efficiency of immediate postoperative inpatient physical therapy following total knee arthroplasty: An RCT. BMC Musculoskelet Disord. 2006;7:no pagination.

84. Levine M, McElroy K, Stakich V, Cicco J. Comparing conventional physical therapy rehabilitation with neuromuscular electrical stimulation after TKA. Orthopedics. 2013;36(3):186-6.

85. Li L, Cheng S, Wang G, Duan G, Zhang Y. Tai chi chuan exercises improve functional outcomes and quality of life in patients with primary total knee arthroplasty due to knee osteoarthritis. Complement Ther Clin Pract. 2019; 35:121-5. https://doi.org/10.1016/j.ctcp.2019.02.003.

86. Liao C-D, Tsauo J-Y, Chiu Y-S, Ku J-W, Huang S-W, Liou T-H. Effects of elastic resistance exercise after Total knee replacement on muscle mass and physical function in elderly women with osteoarthritis: a randomized controlled trial. Am J Phys Med Rehabil. 2020;99(5):381-9. https://doi.org/1 0.1097/PHM.0000000000001344.

87. Liao CD, Liou TH, Huang YY, Huang YC. Effects of balance training on functional outcome after total knee replacement in patients with knee osteoarthritis: a randomized controlled trial. Clin Rehabil. 2013;27(8):697-709. https://doi.org/10.1177/0269215513476722.

88. Liebs TR, Herzberg W, Rüther W, Haasters J, Russlies M, Hassenpflug J. Ergometer cycling after hip or knee replacement surgery: a randomized controlled trial. J Bone Joint Surg (Am Vol). 2010;92(4):814-22. https://doi. org/10.2106/JBJS.H.01359.

89. Liebs TR, Herzberg W, Rüther W, Haasters J, Russlies M, Hassenpflug J, et al. Multicenter randomized controlled trial comparing early versus late aquatic therapy after total hip or knee arthroplasty. Arch Phys Med Rehabil. 2012; 93(2):192-9. https://doi.org/10.1016/j.apmr.2011.09.011.

90. Lowe CJ, Barker KL, Holder R, Sackley CM. Comparison of postdischarge physiotherapy versus usual care following primary total knee arthroplasty for osteoarthritis: an exploratory pilot randomized clinical trial. Clin Rehabil. 2012;26(7):629-41. https://doi.org/10.1177/0269215511427749.

91. Lysack C, Dama M, Neufeld S, Andreassi E. A compliance and satisfaction with home exercise: a comparison of computer-assisted video instruction and routine rehabilitation practice. J Allied Health. 2005;34(2):76-82.

92. Madsen M, Larsen K, Madsen IK, Søe H, Hansen TB. Late group-based rehabilitation has no advantages compared with supervised home-exercises after total knee arthroplasty. Dan Med J. 2013;60(4):A4607.

93. Mahomed NN, Davis AM, Hawker G, Badley E, Davey JR, Syed KA, et al. Inpatient compared with home-based rehabilitation following primary unilateral total hip or knee replacement: a randomized controlled trial. J Bone Joint Surg (Am Vol). 2008;90(8):1673-80. https://doi.org/10.2106/ JBJS.G.01108.

94. McAvoy R. Aquatic and land based therapy vs. land therapy on the outcome of total knee arthroplasty: a pilot randomized clinical trial. J Aquatic Phys Ther. 2009;17(1):8-15.

95. Mitchell C, Walker J, Walters S, Morgan AB, Binns T, Mathers N. Costs and effectiveness of pre- and post-operative home physiotherapy for total knee replacement: randomized controlled trial. J Eval Clin Pract. 2005;11(3):28392. https://doi.org/10.1111/j.1365-2753.2005.00535.x.

96. Mockford BJ, Thompson NW, Humphreys P, Beverland DE. Does a standard outpatient physiotherapy regime improve the range of knee motion after 
primary total knee arthroplasty? J Arthroplast. 2008;23(8):1110-4. https://doi. org/10.1016/j.arth.2007.08.023.

97. Moffet H, Collet JP, Shapiro SH, Paradis G, Marquis F, Roy L. Effectiveness of intensive rehabilitation on functional ability and quality of life after first total knee arthroplasty: a single-blind randomized controlled trial. Arch Phys Med Rehabil. 2004;85(4):546-56. https://doi.org/10.1016/j.apmr.2003.08.080.

98. Moffet H, Tousignant M, Nadeau S, Merette C, Boissy P, Corriveau H, et al. In-home Telerehabilitation compared with face-to-face rehabilitation after Total knee arthroplasty: a noninferiority randomized controlled trial. J Bone Joint Surg. 2015, American volume;97(14):1129-41.

99. Monticone M, Ferrante S, Rocca B, Salvaderi S, Fiorentini R, Restelli M, et al. Home-based functional exercises aimed at managing Kinesiophobia contribute to improving disability and quality of life of patients undergoing Total knee arthroplasty: a randomized controlled trial. Arch Phys Med Rehabil. 2013;94(2):231-9. https://doi.org/10.1016/j.apmr.2012.10.003.

100. Moutzouri M, Gleeson N, Coutts F, Tsepis E, Gliatis J. Early self-managed focal sensorimotor rehabilitative training enhances functional mobility and sensorimotor function in patients following total knee replacement: a controlled clinical trial. Clin Rehabil. 2018;32(7):888-98. https://doi.org/10.11 77/0269215518757291

101. Munin MC, Rudy TE, Glynn NW, Crossett LS, Rubash HE. Early inpatient rehabilitation after elective hip and knee arthroplasty. JAMA. 1998;279(11): 847-52. https://doi.org/10.1001/jama.279.11.847.

102. Paravlic AH, Pisot R, Marusic U. Specific and general adaptations following motor imagery practice focused on muscle strength in total knee arthroplasty rehabilitation: a randomized controlled trial. PLoS One. 2019; 14(8):e0221089. https://doi.org/10.1371/journal.pone.0221089.

103. Paxton RJ, Forster JE, Miller MJ, Gerron KL, Stevens-Lapsley JE, Christiansen $\mathrm{CL}$. A feasibility study for improved physical activity after Total knee arthroplasty. J Aging Phys Act. 2018;26(1):7-13. https://doi.org/10.1123/ja pa.2016-0268.

104. Peiris CL, Taylor NF, Shields N. Additional Saturday allied health services increase habitual physical activity among patients receiving inpatient rehabilitation for lower limb orthopedic conditions: a randomized controlled trial. Arch Phys Med Rehabil. 2012;93(a8):1365-70. https://doi. org/10.1016/j.apmr.2012.03.004

105. Petterson SC, Mizner RL, Stevens JE, Raisis LEO, Bodenstab A, Newcomb W, et al. Improved function from progressive strengthening interventions after total knee arthroplasty: a randomized clinical trial with an imbedded prospective cohort. Arthritis Care Res. 2009;61(2):174-83. https://doi.org/10.1 002/art.24167.

106. Piqueras M, Marco E, Coll M, Escalada F, Ballester A, Cinca C, et al. Effectiveness of an interactive virtual telerehabilitation system in patients after total knee arthroplasty: a randomized controlled trial. J Rehabil Med. 2013;45(4):392-6. https://doi.org/10.2340/16501977-1119.

107. Piva SR, Almeida GJ, Gil AB, DiGioia AM, Helsel DL, Sowa GA. Effect of comprehensive behavioral and exercise intervention on physical function and activity participation after Total knee replacement: a pilot randomized study. Arthritis Care Res. 2017;69(12):1855-62. https://doi.org/10.1002/acr.23227.

108. Piva SR, Gil AB, Almeida GJM, DiGioia lii AM, Levison TJ, Fitzgerald GK. A balance exercise program appears to improve function for patients with Total knee arthroplasty: a randomized clinical trial. Phys Ther. 2010;90(6): 880-94. https://doi.org/10.2522/ptj.20090150.

109. Prvu Bettger J, Green CL, Holmes DN, Chokshi A, Mather RC, Hoch BT, et al. Effects of virtual exercise rehabilitation in-home therapy compared with traditional care after Total knee arthroplasty: VERITAS, a randomized controlled trial. J Bone Joint Surg. 2020, American volume;102(2):101-9.

110. Rajan RA, Pack Y, Jackson H, Gillies C, Asirvatham R. No need for outpatient physiotherapy following total knee arthroplasty: a randomized trial of 120 patients. Acta Orthop Scand. 2004;75(1):71-3. https://doi.org/10.1080/000164 70410001708140.

111. Roig-Casasús S, Blasco JM, López-Bueno L, Blasco-Igual MC. Balance training with a dynamometric platform following Total knee replacement: a randomized controlled trial. J Geriatr Phys Ther. 2018;41(4):204-9. https:// doi.org/10.1519/JPT.0000000000000121.

112. Russell TG, Buttrum P, Wootton R, Jull GA, Russell TG, Buttrum $P$, et al. Internet-based outpatient telerehabilitation for patients following total knee arthroplasty: a randomized controlled trial. J Bone Joint Surg (Am Vol). 2011; 93(2):113-20. https://doi.org/10.2106/JBJS.I.01375.

113. Russo LR, Benedetti MG, Mariani E, Roberti di Sarsina T, Zaffagnini S. The Videoinsight ${ }^{\oplus}$ method: improving early results following total knee arthroplasty. Knee Surg Sports Traumatol Arthrosc. 2017;25(9):2967-71. https://doi.org/10.1007/s00167-016-4118-x.

114. Sattler LN, Hing WA, Vertullo CJ. Pedaling-based protocol superior to a 10exercise, non-pedaling protocol for postoperative rehabilitation after Total knee replacement: a randomized controlled trial. J Bone Joint Surg (Am Vol). 2019:101(8):688-95. https://doi.org/10.2106/JBJS.18.00898.

115. Shabbir M, Umar B, Ehsan S, Munir S, Bunin U, Sarfraz K. Comparison of functional training and strength training in improving knee extension lag after first four weeks of total knee replacement. Biomed Res (Aligarh). 2017; 28(12):5623-7.

116. Shanb AS, Youssef EF. Effects of adding biofeedback training to active exercises after total knee arthroplasty. J Musculoskelet Res. 2014;17(01): 1450001.

117. Smith WA, Zucker-Levin A, Mihalko WM, Williams M, Loftin M, Gurney JG. A randomized study of exercise and fitness trackers in obese patients after Total knee arthroplasty. Orthop Clin North Am. 2019;50(1):35-45. https://doi. org/10.1016/j.ocl.2018.08.002.

118. Stevens-Lapsley JE, Balter JE, Wolfe P, Eckhoff DG, Kohrt WM. Early neuromuscular electrical stimulation to improve quadriceps muscle strength after Total knee arthroplasty: a randomized controlled trial. Phys Ther. 2012; 92(2):210-26. https://doi.org/10.2522/ptj.20110124.

119. Tanaka R, Hayashizaki T, Taniguchi R, Kobayashi J, Umehara T. Effect of an intensive functional rehabilitation program on the recovery of activities of daily living after total knee arthroplasty: a multicenter, randomized, controlled trial. J Orthop Sci. 2020;25(2):285-90. https://doi.org/10.1016/j. jos.2019.04.009.

120. Tanaka Y, Oka H, Nakayama S, Ueno T, Matsudaira K, Miura T, et al. Improvement of walking ability during postoperative rehabilitation with the hybrid assistive limb after total knee arthroplasty: A randomized controlled study. SAGE Open Med. 2017;5:no pagination.

121. Timmers T, Janssen L, Van der Weegen W, Das D, Marijnissen W-J, Hannink G, van der Zwaard BC, Plat A, Thomassen B, Swen J-W, et al. The Effect of an App for Day-to-Day Postoperative Care Education on Patients With Total Knee Replacement: Randomized Controlled Trial. Jmir Mhealth and Uhealth. 2019;7(10):e15323.

122. Tousignant M, Moffett H, Boissy P, Corriveau H, Cabana F, Marquis F. A randomized controlled trial of home telerehabilitation for post-knee arthroplasty. J Telemed Telecare. 2011;17(4):195-8. https://doi.org/10.1258/ jtt.2010.100602.

123. Trudelle-Jackson E, Hines E, Medley A, Thompson M. Exploration of habitual walking behavior and home-based muscle power training in individuals with total knee arthroplasty. J Phys Act Health. 2020;17(3):331-8.

124. Unver B, Bakirhan S, Karatosun V. Does a weight-training exercise programme given to patients four or more years after total knee arthroplasty improve mobility: a randomized controlled trial. Arch Gerontol Geriatr. 2016;64:45-50. https://doi.org/10.1016/j.archger.2016.01.003.

125. Valdes Vilches M, Fernandez Ferreras T, Serra Tarragon N, Bujedo Pertejo A, San Segundo Mozo R, Molins Roca J. Feedback and neuromuscular electrical stimulation during an early phase of a rehabilitation programe after total knee arthroplasty. [Spanish]. Trauma (Spain). 2010;21(3):163-8.

126. Valtonen $A$, Poyhonen $T$, Sipila $S$, Heinonen A. Effects of aquatic resistance training on mobility limitation and lower-limb impairments after knee replacement. Arch Phys Med Rehabil. 2010;91(6):833-9. https://doi.org/10.1 016/j.apmr.2010.03.002

127. Vuorenmaa M, Ylinen J, Piitulainen $K$, Salo P, Kautiainen $H$, Pesola M, et al. Efficacy of a 12-month, Monitored Home Exercise Programme Compared with Normal Care Commencing 2 months After Total Knee Arthroplasty: A Randomized Controlled Trial. J Rehabil Med. 2014;46(2):166-72.

128. Woźniak-Czekierda W, Woźniak K, Hadamus A, Białoszewski D. Use of kinesiology taping in rehabilitation after knee arthroplasty: a randomised clinical study. Ortop Traumatol Rehabil. 2017;19(5):461-8.

129. Yousefian Molla R, Sadeghi H, Kahlaee AH. The effect of early progressive resistive exercise therapy on balance control of patients with Total knee arthroplasty. Top Geriatr Rehabil. 2017;33(4):286-94. https://doi.org/10.1097/ TGR.0000000000000165.

130. Zietek P, Zietek J, Szczypior K, Safranow K. Effect of adding one 15-minutewalk on the day of surgery to fast-track rehabilitation after total knee arthroplasty: a randomized, single-blind study. Eur J Phys Rehabil Med. 2015; 51(3):245-52.

131. Lin YH, Lee SY, Su WR, Kao CC, Tai TW, Chen TB. Effects of nurse-led lower extremity strength training on knee function recovery in patients who 
underwent total knee replacement. J Clin Nurs. 2018;27(9-10):1836-45. https://doi.org/10.1111/jocn.14368.

132. Gianola S, Castellini G, Agostini M, Bolotta R, Corbetta D, Frigerio P, et al. Reporting of rehabilitation intervention for low back pain in randomized controlled trials: is the treatment fully replicable? Spine (Phila Pa 1976). 2016;41(5):412-8. https://doi.org/10.1097/BRS.0000000000001290.

133. Pino C, Boutron I, Ravaud P. Inadequate description of educational interventions in ongoing randomized controlled trials. Trials. 2012;13(1):63. https://doi.org/10.1186/1745-6215-13-63.

134. Reid JC, Unger J, McCaskell D, Childerhose L, Zorko DJ, Kho ME. Physical rehabilitation interventions in the intensive care unit: a scoping review of 117 studies. J Intensive Care. 2018;6(1):80. https://doi.org/10.1186/s40560-01 8-0349-x.

135. Chakrabarti S. What's in a name? Compliance, adherence and concordance in chronic psychiatric disorders. World J Psychiatry. 2014;4(2):30-6. https:// doi.org/10.5498/wjp.v4.i2.30.

136. Bailey DL, Holden MA, Foster NE, Quicke JG, Haywood KL, Bishop A. Defining adherence to therapeutic exercise for musculoskeletal pain: a systematic review. Br J Sports Med. 2020;54(6):326-31.

137. Linke SE, Gallo LC, Norman GJ. Attrition and adherence rates of sustained vs. intermittent exercise interventions. Ann Behav Med. 2011;42(2):197-209. https://doi.org/10.1007/s12160-011-9279-8

138. Boutron I, Guittet L, Estellat C, Moher D, Hróbjartsson A, Ravaud P. Reporting methods of blinding in randomized trials assessing nonpharmacological treatments. PLoS Med. 2007;4(2):e61. https://doi.org/10.1371/journal.pmed. 0040061.

139. Halm EA, Lee C, Chassin MR. Is volume related to outcome in health care? A systematic review and methodologic critique of the literature. Ann Intern Med. 2002;137(6):511-20. https://doi.org/10.7326/0003-4819-137-6-2002091 70-00012.

140. Jack K, McLean SM, Moffett JK, Gardiner E. Barriers to treatment adherence in physiotherapy outpatient clinics: a systematic review. Man Ther. 2010; 15(3):220-8. https://doi.org/10.1016/j.math.2009.12.004.

\section{Publisher's Note}

Springer Nature remains neutral with regard to jurisdictional claims in published maps and institutional affiliations.

Ready to submit your research? Choose BMC and benefit from:

- fast, convenient online submission

- thorough peer review by experienced researchers in your field

- rapid publication on acceptance

- support for research data, including large and complex data types

- gold Open Access which fosters wider collaboration and increased citations

- maximum visibility for your research: over $100 \mathrm{M}$ website views per year

At $\mathrm{BMC}$, research is always in progress.

Learn more biomedcentral.com/submissions 